\title{
RELAÇÕES DE SAÚDE E TRABALHO EM ASSENTAMENTO RURAL DO MST NA REGIÃO DE FRONTEIRA BRASIL-PARAGUAI
}

\author{
HEALTH AND WORK RELATIONS IN A RURAL SETTLEMENT OF THE MST IN THE BRAZIL-PARAGUAY \\ BORDER REGION
}

\author{
Eduardo Espíndola Fontoura Júnior ${ }^{1}$ \\ Kátia Reis de Souza ${ }^{2}$ \\ Rogério Dias Renovato ${ }^{3}$ \\ Cibele de Moura Sales ${ }^{4}$
}

Resumo Com o presente artigo, busca-se relatar e analisar as relações entre saúde e trabalho de pequenos produtores rurais do Movimento dos Trabalhadores Rurais Sem Terra (MST). Quanto à metodologia, adotou-se o aporte da investigação participativa e as bases da educação popular. O estudo realizado tornou possível uma compreensão de saúde e de trabalho mediante as narrativas dos trabalhadores e histórias relativas às lutas coletivas contra a exclusão e a violência no campo. Constataram-se importantes aspectos próprios a esse grupo populacional, como o sentido de conquista da propriedade da terra, os conflitos advindos da 'militância' e as diferenças de gênero e geração. Com base nos relatos, analisaram-se também os acidentes e os riscos relacionados à atividade de trabalho no assentamento rural, principalmente a exposição ao agrotóxico. Confirmaram-se, ainda, a solidariedade e a cooperação como valores importantes e como base de novas relações, um modo distinto de organização social coletiva do trabalho.

Palavras-chave saúde; trabalhador rural; MST; assentamento rural; agrotóxicos.

\begin{abstract}
In this article, we aim to report on and analyze the relationship between health and work of small farmers of the Landless Workers Movement (MST). So far as the methodology is concerned, we used participatory research and the basics of popular education. The study allowed for an understanding of health and work based on the workers' narratives, stories relating to collective struggles against exclusion and violence in the countryside. Important aspects related to this population group as were discovered, such as, for example, the sense of conquest of land ownership, the conflicts arising from 'activism,' and the differences of gender and generations. From the reports that were provided, we also examined the accidents and risks related to work in the rural settlement, particularly exposure to pesticides. It was also found that solidarity and cooperation are important values, basic elements for new relations and a distinctive mode of social organization of collective.
\end{abstract}

Keywords health; rural worker; MST; rural settlements; pesticides. 


\section{Introdução}

Com o presente artigo, busca-se relatar e analisar as relações entre saúde e trabalho de pequenos produtores rurais do Movimento dos Trabalhadores Rurais Sem Terra (MST), tendo por base uma pesquisa realizada em assentamento rural localizado na região sul do estado de Mato Grosso do Sul.

Considerado um dos maiores territórios de reforma agrária do país, o assentamento em questão é conhecido como 'Fazenda Itamaraty'. Trata-se de uma área com 50 mil hectares de terra que está localizada no município de Ponta Porã, fronteira com o Paraguai, na região sul de Mato Grosso do Sul.

Dados do Instituto Nacional de Colonização e Reforma Agrária (Incra) registraram, em março de 2003, 17.187 famílias assentadas em 115 projetos de assentamento naquele estado. Em 2001, foi criado o Assentamento Fazenda Itamaraty, localizado a $45 \mathrm{~km}$ da sede do município e a $21 \mathrm{~km}$ da faixa de fronteira com o Paraguai. Nesse local, foram assentadas 1.145 famílias indicadas por quatro movimentos sociais, dentre eles o Departamento Estadual dos Trabalhadores Rurais (DETR) da Central Única dos Trabalhadores (CUT), o Movimento dos Trabalhadores Rurais Sem Terra (MST), a Federação dos Trabalhadores na Agricultura do Estado de Mato Grosso do Sul (Fetagri) e a Associação dos Funcionários da Fazenda Itamaraty (AMFFI). Apesar de essas quatro organizações de trabalhadores terem posicionamentos político-ideológicos distintos, a Superintendência do Incra/MS decidiu congregar e estabelecer parcerias com os principais movimentos de trabalhadores rurais, objetivando o assentamento de famílias que compunham suas bases. A perspectiva era uma ação de reordenamento fundiário da região, propiciando a construção de novas unidades de produção, com base na economia de agricultura familiar (Terra, 2009).

Neste estudo, tratou-se do Grupo 17, que é parte do assentamento do MST da Fazenda Itamaraty. Também denominado de Grupo Coletivo Eldorado dos Carajás, é o único, de todo o assentamento, com área totalmente coletiva. Segundo Terra (2009), o Grupo 17 tem como diferencial o fato de ser composto por pessoas que foram lideranças e militantes na época de acampamento e do processo de implantação do Assentamento Itamaraty. Outro importante diferencial diz respeito ao fato de esse grupo desenvolver todas as atividades coletivamente. Trata-se de aproximadamente 317 hectares de terra de uso coletivo. Nenhuma família tem direito privado. Talvez este seja o ponto crucial da rejeição a esse modelo de gestão por parte dos demais assentamentos da região. De acordo com Terra (2009), faz parte da cultura do trabalhador do campo pensar na terra como uma herança para seus filhos, e neste caso não há nenhum bem material com valor monetário. Assim, há impedimento da comercialização do lote pelo assentado, uma vez que ele detém apenas o usufruto do bem. 
Antes, a Fazenda Itamaraty era um conhecido latifúndio de monocultura de soja, principalmente durante as décadas de 1970 e 1980, e foi considerada um símbolo ideológico de desenvolvimento rural: maior área irrigada do campo no país e com a maior produção de soja da América Latina, conferindo ao seu administrador o 'título' de 'rei da soja'. A rigor, o cultivo da soja era realizado em grande escala e destinava-se, sobretudo, ao comércio de exportação. Para os trabalhadores rurais pesquisados neste estudo, aspectos como o desmatamento da região, a degradação ambiental (solo, água e fauna) e o uso intensivo de agrotóxico levaram a Fazenda Itamaraty à situação de 'latifúndio insustentável' . Além disso, vale mencionar as denúncias de irregularidades, como o desvio de verba pública, culminando na falência de todo esse complexo rural e no consequente abandono da terra, além da indignação dos trabalhadores, que passaram a lutar, organizadamente, pela posse da terra (Bernardes, Fontoura Júnior e Pereira, 2006).

Cabem aqui, inicialmente, algumas observações relativas ao Movimento dos Trabalhadores Rurais Sem Terra, também conhecido como Movimento dos Sem Terra, ou MST. Este é fruto de uma questão agrária, estrutural e histórica no Brasil. Nasceu da articulação das lutas pela terra que foram retomadas a partir do final da década de 1970, especialmente na região centro-sul do país, expandindo-se aos poucos. O MST teve sua gestação no período de 1979 a 1984. O movimento foi criado, formalmente, no $1^{\circ}$ Encontro Nacional de Trabalhadores Sem Terra, que aconteceu de 21 a 24 de janeiro de 1984, em Cascavel, no estado do Paraná. Hoje, o MST está organizado em 22 estados e segue com os mesmos objetivos definidos nesse encontro de 1984: lutar pela terra, pela reforma agrária e pela construção de uma sociedade mais justa, sem explorados nem exploradores (Caldart, 2001).

Do ponto de vista político e ideológico, o processo de reforma agrária ocorrido nessa região representou para o movimento social do campo uma importante conquista dos trabalhadores rurais na luta pelo uso coletivo da terra. Significou também uma ruptura com o modelo do agronegócio, cuja ênfase é a 'racionalidade' dos lucros privados, da competitividade e dos interesses de mercado. Tanto a ocupação do território quanto a organização das famílias e ainda a produção de alimentos do assentamento ocorrem dentro de padrões coletivos que beneficiam, de forma equitativa, todas as famílias que compõem o grupo. Além de se constituir como regra ou norma, a ideia de coletivo para o MST significa a socialização do direito à terra e ao trabalho como um princípio que se baseia em valores como cooperação, democracia e preservação da vida e da natureza.

Para Hobsbawm (1995, p. 300), a ideia de coletividade é elemento simbólico central do movimento e da vida dos trabalhadores: "o domínio do nós sobre o eu". O que dá aos partidos e movimentos de trabalhadores sua força original é a justificada convicção dos trabalhadores de que pessoas 
como eles não podem melhorar a sua sorte pela ação individual, mas só pela ação coletiva, de preferência por meio de organizações, seja pela ajuda mútua, seja pela greve ou pelo voto.

Este estudo possibilitou-nos entender que o MST afirma, em suas iniciativas, novas relações sociais e um novo projeto de desenvolvimento para o campo e para o país. As áreas de latifúndios conquistadas tornaram-se lugares de vida e de trabalho para muitas famílias, e de produção de alimentos para outras tantas. A investigação realizada tornou possível uma compreensão a respeito da relação entre saúde e trabalho, com base nas narrativas dos trabalhadores e em histórias relativas às lutas coletivas contra a exclusão e a violência no campo.

\section{Metodologia}

O grupo pesquisado do MST é conhecido como Grupo 17 do Assentamento Itamaraty. Na ocasião da pesquisa, era composto de 19 famílias com 54 pessoas, entre as quais 18 homens, 12 mulheres e 24 crianças e adolescentes. Os participantes deste estudo eram, em grande maioria, 'brasiguaios' (denominação comum dada a cidadãos brasileiros que saíram do país para tentar trabalhar no Paraguai, país vizinho, e que retornaram ao Brasil atraídos pelo projeto de assentamento na região possibilitado pelo movimento de reforma agrária).

Uma das idéias centrais desenvolvidas nos limites deste estudo é a concepção dos indivíduos como sujeitos de saberes e de valores (e não como objetos) adquiridos ao longo de suas vidas. Sobre essa base de compreensão, adotou-se o aporte metodológico da investigação participativa e as bases da educação popular (Freire, 1986, 1988; Brandão, 1986, 2006), que, em resumo, configuram-se como processos de aprendizagem coletiva por meio de práticas grupais - práticas estas que visualizam participação, investigação e ações educativas como momentos de um mesmo processo e que ainda se inscrevem numa perspectiva de contribuir, por meio do diálogo, para mudanças sobre a realidade investigada (Gajardo, 1987). Busca-se conjugar, com esses materiais, a produção de conhecimento e diálogo entre trabalhadores e pesquisadores sobre a realidade dos problemas referentes à relação entre trabalho e saúde dos pequenos produtores rurais com vistas à sua transformação.

Para tanto, realizamos seis reuniões em caráter aberto, ou seja: permitia-se a participação de qualquer pessoa do assentamento em todos os encontros sem a exigência de continuidade, embora se tenha observado que o número de pessoas se manteve estável desde a primeira reunião (aproximadamente vinte pessoas por reunião). Cabe a observação de que todos os 
encontros foram realizados na sede do assentamento, com o objetivo de nos inserirmos na realidade e estarmos mais próximos do seu cotidiano.

De forma geral, adotando esse método, pretende-se expandir a capacidade dessas pessoas de analisarem a saúde (sua e do seu grupo) valorizando o pensar e a experiência do trabalho. Ao longo das reuniões, os conteúdos dos diálogos foram registrados (gravados e transcritos) e considerados como objetos relevantes de investigação. Obteve-se um amplo e complexo material para análise, tendo sido necessário realizar um exercício de seleção e identificação dos principais temas geradores dos debates (Freire, 1988), com a intenção de se analisar a relação entre trabalho, modos de vida e saúde dos trabalhadores rurais. Cabe, entretanto, um detalhamento quanto ao processo de produção de conhecimento da pesquisa participante baseado no pensamento de Freire e Brandão: na vertente teórica da educação popular, mais do que se constituir como pedra angular da relação pedagógica da pesquisa, o diálogo possibilita a identificação de temas, que são matéria para a análise (qualitativa) dos dados de investigação. Assim, o material transcrito dos diálogos entre os trabalhadores tornou-se o nosso texto de análise. Apoiados no referencial da pesquisa qualitativa, adotou-se complementarmente, como procedimento de tratamento de estudo desses textos, a análise do discurso (Gill, 2008). Nessa perspectiva, o discurso tem uma importância central na construção da vida social: "o discurso é construído ou manufaturado pelos diversos atores sociais" (Gill, 2008, p. 247). Trata-se de uma posição epistemológica com ênfase na interpretação da linguagem e do contexto. Desse modo, foi possível 'selecionar' os temas centrais de nossa análise, que, com Freire (1988), são chamados de 'temas geradores'. Organizaram-se os resultados, nessa perspectiva, selecionando aqueles temas que foram os principais geradores do diálogo, o que nos possibilitou um percurso dialógico de ordenação dos materiais de pesquisa. Destacaram-se os seguintes temas que se constituem em nossas categorias (empíricas) de análise: a história e a formação do assentamento; reforma agrária; trabalho coletivo; cidadania; trabalho infantil; relações de gênero; relações familiares e geracionais; exclusão social e violência; processo de trabalho; saúde dos trabalhadores; agrotóxicos; acidentes e riscos nas atividades de trabalho.

\section{Resultados e discussão}

\section{A luta pela reforma agrária e a formação do assentamento}

Os relatos dos trabalhadores mostram as dificuldades em se construir um projeto de organização coletiva no assentamento com base, sobretudo, em valores como liberdade, justiça social e socialização da produção. É um 
projeto que objetiva alcançar relações humanas e de trabalho mais igualitárias, menos injustas, e que se constrói na luta cotidiana pelo uso democrático da terra. Nas falas dos trabalhadores, observou-se o sentido de trabalho associado ao de liberdade.

Antes [na antiga fazenda] não existia liberdade, antes era aquela escravidão de viver trabalhando pro patrão, era muito sofrimento. A gente quer colocar essa ideia de 'devolver a vida', pois, com a conquista da terra, tivemos a oportunidade de construir e reconstruir a vida. A maioria dos funcionários da antiga fazenda reconhece que agora é deles, fazem do jeito deles (Trabalhador 3).

Confirmou-se uma noção de trabalho que se contrapõe a um modelo de trabalho característico de uma sociedade de mercado. Segundo Mészáros (2004), a concepção de trabalho como atividade a que os indivíduos se dedicam livremente para se realizarem como indivíduos particulares, como pessoas verdadeiras, é compatível com a concepção socialista de atividade produtiva, em que a autoridade é livremente 'autoconstituída' de forma associada, pelos próprios trabalhadores-produtores. Tomando como base o pensamento de Marx, Mészáros (2004) afirma que a verdadeira liberdade como condição social tangível só pode consistir no homem 'socializado', condição segundo a qual o trabalho possa ser abraçado pelos indivíduos como “a principal necessidade da vida” (Mészáros, 2004, p. 533).

Percebem-se, nas diversas narrativas, a solidariedade e a cooperação como valores importantes, como a base de novas relações e de uma nova forma de organização social coletiva. Há uma corresponsabilização de todos para a melhoria das condições de vida local, socializando a produção, os recursos e o saber advindo da experiência do trabalho.

Segundo Scopinho (2007), a cooperação, entendida como ação social espontânea ou organizada, sempre foi essencial para o MST, desde a sua origem. É entendida como um processo de aprendizagem de longo tempo, que se inicia nos acampamentos antes mesmo da posse da terra e assume diferentes formas, conforme se transformam as condições objetivas da realidade. Os dirigentes enfatizam que a luta pela terra é, por excelência, a experiência de cooperação mais importante para um sem-terra. Essa dimensão da cooperação é favorecedora de condições para desenvolver a sociabilidade nos assentamentos; aliada à geração de renda, é essencial para possibilitar a permanência das famílias nos assentamentos e evitar novos êxodos rurais. A cooperação organizativa e a solidariedade militante garantem a logística que sustenta a luta social pela conquista e permanência na terra. Tal dimensão revela-se também no cotidiano dos acampamentos e assentamentos por meio da repartição do que se arrecada ou se produz de alimentos, da 
troca de favores entre as famílias, das pequenas ações de ajuda mútua sem as quais não haveria condições de sustentar e ampliar a capacidade de resistência (Scopinho, 2007).

Segundo relatos dos trabalhadores, a luta pela posse da terra possibilita a construção de relações de solidariedade entre eles, independentemente de terem algum grau de parentesco. Tiriba (1998) afirma que, quando o povo organiza processos de produção, existe a tendência de que o faça de forma cooperativa e solidária, de maneira a contrariar a lógica da organização capitalista do trabalho. No caso dos sem-terra, apesar das dificuldades e dos diversos impedimentos, eles contam com a solidariedade do grupo.

Em relação à organização política do assentamento, os trabalhadores desenvolvem um sistema de gestão com ênfase nas decisões coletivas. Observou-se a democracia como base das relações de trabalho, contribuindo para o processo de emancipação das pessoas: todos têm o direito a voz e voto nas deliberações. Durante as reuniões, ficou claro que a ideia de coletivo tem uma conotação ideológica que diz respeito à organização política dos trabalhadores - contra-hegemônica - de forma a criar relações de novo tipo (Gramsci, 1986). Além disso, nota-se um sentido de corresponsabilidade coletiva que se apoia no engajamento individual permanente. O termo 'nós' parece reafirmar a idéia de organização e conquista coletiva (Correia et al., 2007), expressando-se como símbolo numa forma muito própria de lutar do MST pelo lema: 'ocupar, produzir, resistir' (Silva, 2009).

A gente já conhecia a proposta coletiva como uma proposta que dá certo. Como já era de nosso conhecimento, viemos para cá ajudar a construir, morar aqui, enterrar o umbigo nesse lugar (...) então vieram todos somar conosco, discutimos tudo, saiu a proposta do grupo coletivo. No primeiro momento alguns concordaram, outros foram embora (Trabalhador 2).

O recorte de gênero é um importante ângulo a ser considerado diante das narrativas que relacionaram, diferentemente, as histórias de vida e de trabalho de homens e de mulheres. Houve, ainda, relatos de trabalho infantil como algo que se tornou parte da rotina do trabalho rural. É comum que meninas, muito cedo, tomem conta da casa ou cuidem de seus irmãos menores. É imposta às mulheres a responsabilidade precoce pelos ambientes domésticos. Por sua vez, aos meninos cabe a responsabilidade antecipada de trabalho na fazenda, onde aprendem o trabalho com os mais velhos.

Eu comecei a trabalhar aos 9, que minha avó tinha problema de saúde e não dava conta da casa; então, eu meio que morava, vinha só dormir na nossa casa e ia para casa dela cedo para fazer todo o serviço (Trabalhador 1). 
Comecei a trabalhar com 7 anos de idade. Na fazenda mesmo. Lá era leiteria, tirávamos leite e eu aprendi a tirar leite; eu e meus dois irmãos ajudávamos meu pai a tirar leite na fazenda (Trabalhador 4).

Para Oliveira (1992), a dicotomia sexual divide a sociedade em duas metades: é um dualismo hierarquizado que atravessa e penetra todas as dimensões da vida e determina um processo diferenciado de transmissão e de aquisição de conhecimentos, valores e modos de comportamento. Relacionase ao campo dos atributos e qualidades sexuais uma conformação diferenciada na forma como estão ocupados os lugares entre homens e mulheres, e que se exprime em diferenças e complementaridades. Estabelecer novas relações por meio do trabalho coletivo no assentamento supõe construir novas relações de gênero nas quais homens e mulheres ocupem lugares compartilhados, sem hierarquias. Desde sua fundação, o objetivo primário do MST tem sido a luta pela reforma agrária e por 'uma sociedade justa e igualitária'. O movimento reconheceu que, para realizar isso, “a participação de todos os trabalhadores rurais" era necessária, "estimulando a participação das mulheres em todos os níveis" (Deere, 2004, p. 186). As mulheres têm sido muito visíveis na condução das ocupações de terra do MST (estima-se que elas sejam entre um terço e a metade dos participantes), e muitas vezes estão na linha de frente nos confrontos com a polícia. Além disso, as mulheres, geralmente, desempenham um papel-chave e muito ativo nos acampamentos que resultam dessas ocupações. No entanto, uma vez que os acampamentos estão constituídos, poucas mulheres participam de forma tão ativa; até recentemente, havia poucas mulheres em sua liderança ou na do MST. Conforme nos assegura Deere (2004):

Todavia observamos que, depois da conquista da terra, nos assentamentos, um grande número de mulheres volta a fazer apenas trabalho interno, na roça, em casa ou com as crianças. Por isso, é necessário que as mulheres se organizem e participem da luta da classe trabalhadora em todas as suas instâncias (Deere, 2004, p. 187).

Além do tema 'gênero', outro importante assunto que fez parte do repertório temático dos diálogos diz respeito à relação entre trabalho infantil, geração e militância. Pelos relatos dos trabalhadores, há trabalho infantil no espaço doméstico e na lavoura do assentamento. Houve relatos daqueles que tiveram seus pais no movimento de luta pela reforma agrária e que se ressentiam da ausência desses em casa, o que inclusive levou-os a assumir, ainda muito cedo, responsabilidades familiares. É importante voltar o olhar para o cotidiano da infância e da adolescência num acampamento do MST. Há uma construção de identidade coletiva e de uma cultura de infância em relação à condição de sem-terra. Conforme os estudos de Correia et al. (2007), 
os discursos e as práticas de crianças do MST não apenas mostram a importância do pertencimento a um movimento social organizado na estruturação de sua identidade, mas também indicam que a luta vai se apresentando como uma vivência educativa total.

No processo de luta, de organização, de trabalho, de cooperação e de vida dos sem-terra ligados ao MST, é possível perceber que a educação é expressão de todas essas dinâmicas construídas coletivamente, ou seja, ela é constituída pelas relações sociais, mas é também constituinte. Isso significa dizer que o processo educativo vivido instrumentaliza os trabalhadores para o seu trabalho, para a cooperação, para as lutas junto ao MST, ao partido político, à militância ecológica e às mulheres acampadas e assentadas (Vendramini, 2007).

Outro aspecto curioso relatado nas reuniões foi relativo à intensa dedicação dos assentados à militância no MST, e às tensões e conflitos entre pais e filhos provocados por essa dedicação no âmbito das relações familiares. Os trabalhadores relataram, no decurso dos diálogos, alguns significados sobre a infância no interior de um movimento social e a consequente tensão entre o grupo geracional adulto e o infantil.

É, praticamente a gente cresceu vendo os pais na militância. Eu era contra até os 17 anos, tinha aquela rebeldia de nunca ter meus pais junto com a gente. Ficava aquela revolta de que a gente perdia os pais para a luta. A gente não entendia toda essa questão da luta, a gente era muito contra. É devido a essa questão, dessa complexidade, que eu não compreendia. Meu pai tinha compromisso muito forte com o movimento e não cedia aos meus caprichos (Trabalhador 1).

No Paraguai, eu comecei a trabalhar desde pequeno, com uns oito anos já trabalhava (Trabalhador 8).

É, dos 9 anos aos 15, eu fiquei fazendo essa lida todo dia, com 15 anos. É, a minha infância todinha foi sem meu pai e sem minha mãe, porque os dois eram de movimentos sociais (Trabalhador 1).

Em estudo realizado com crianças do MST (Correia et al., 2007), constatou-se o processo de estruturação de identidade de crianças do MST, construída pelo pertencimento a um movimento social organizado. O trabalho com a terra foi algo destacado pelas crianças na pesquisa, indicando que o trabalho no campo constitui-se como um processo de aprendizagem permanente, com a aquisição de novos conhecimentos definidos pela relação com a terra ao longo de gerações. Em todo o Brasil, são mais de 160.000 crianças e adolescentes que estudam em escolas de acampamentos e assentamentos do MST. Há o reconhecimento da construção de uma identidade de sem-terra 
desde a infância proporcionada pelo próprio movimento. Vale mencionar a existência na estrutura do MST do 'Movimento dos Sem Terrinha', já que uma das características da sua luta é exatamente a presença de toda a família.

A alta rotatividade das famílias no campo é muito grande. Além da precarização dos vínculos e dos salários baixos, a mecanização desemprega muitos trabalhadores, principalmente os de idade avançada. O sofrimento e a insegurança são sentimentos que levam os trabalhadores rurais a se inserirem no movimento social, proporcionando a esperança de conseguirem uma pequena propriedade para produzir seu sustento e o de sua família de forma autônoma, não dependendo de patrão. Os trabalhadores reconhecem na luta pela terra uma das estratégias mais eficazes contra o latifúndio improdutivo, favorecendo a construção da justiça social no campo. Afirmam, ainda, o desejo de que o projeto de reforma agrária, consubstanciado em assentamentos, possibilite que seus filhos possam estudar e viver com dignidade. Segundo Stédile (2000), historicamente a luta pela terra carrega a característica de ser uma luta dos pobres. O pertencimento de classe é algo central nesse processo. Conforme relato do trabalhador a seguir:

Nossa expectativa, principalmente a minha; sabemos da realidade da reforma agrária. Não queremos enriquecer com ela. Nós queremos uma condição de vida melhor para todos, incluindo nossa família, e nossas crianças que têm o que comer: arroz, feijão, uma mistura e ter um dinheirinho, para ajudar nossas crianças a se qualificar. Esse é meu objetivo, onde possam viver com dignidade com autonomia de grupo (Trabalhador 3).

A violência contra o trabalhador rural sem-terra foi outro importante tema gerador dos debates. Trata-se de uma violência que é conhecida e veiculada pelos meios de comunicação de massa e que parece estar banalizada. Segundo os relatos dos trabalhadores, a violência contra aqueles que lutam pela posse da terra é justificável por uma lógica do proprietário; por isso, eles são rotulados muitas vezes como 'baderneiros'.

Fomos todo mundo, a família, somos em [sic] quatro irmãos; aí fomos todos pro acampamento, aí ficamos sete anos acampado. Daqui de Novo Horizonte, nós rodamos: o Vale de Ivinhema ali onde pega Nova Andradina, Casa Verde, Bataiporã, Anaurilândia, e nós moramos por aqui, assim. Aí a gente ficou acampando quase oito anos; então, assim, era uma época difícil porque o governador do estado na época era muito contra esse processo de reforma agrária; muito contra, assim, o povo que ocupava a fazenda tal. Então era uma época de muito despejo e de muito despejo violento. Então nós chegávamos a ocupar uma fazenda quatro horas da manhã e quando eram oito horas nós saíamos debaixo de bala, não tinha muita prosa, não (Trabalhador 4). 
A compreensão a que chegamos ao se enfocar a violência no campo é que se trata de uma manifestação da violência estrutural, que é um aspecto da organização social mais ampla. As instituições sociais no modo de produção capitalista, muitas vezes o próprio Estado, podem ser perpetradoras de violência, criando situações nas quais uma parcela da sociedade seria estruturalmente desfavorecida (Campos, 2002). Para Comparato (2001), uma linha de conduta adotada pela imprensa e por alguns governos para enfrentar a pressão exercida pelo MST é tentar descaracterizá-lo como movimento social, para enquadrá-lo como um movimento criminoso, que realiza um conjunto de ações fora da lei. Seja como for, para esse autor, o Movimento dos Sem Terra é hoje um ator de primeira grandeza na cena política, quer pelo assentamento legal dos invasores, quer pela permanência deles nas terras ocupadas, quer pelo convencimento das autoridades públicas de que não se deve impor o respeito à lei, mas aceitar as invasões e negociar.

Durante as reuniões da pesquisa, os trabalhadores afirmavam acreditar que os assentamentos pudessem servir de exemplo de empreendimento (exitoso) da reforma agrária no que se refere a ações de transformação do trabalho e da vida, principalmente, investindo-se na conservação da natureza local, na coletivização da produção e, consequentemente, na melhoria da qualidade de vida da população. Tiveram ênfase outros temas como a dignidade do trabalhador rural, o renascimento silvestre da região do assentamento e, com isso, o retorno de espécies animais extintas. E ainda: o tratamento da água e a coletivização da produção, acompanhada pelo aumento da natalidade e da expectativa de vida.

Debateu-se a agricultura familiar como um importante aspecto do desenvolvimento local, pois ela propicia uma perspectiva de maior sustentabilidade social e econômica. Antes, na antiga Fazenda Itamaraty, além da monocultura de soja, criavam-se cavalos em haras e empregava-se mão de obra com baixa remuneração. Segundo Vendramini (2007), a modernização da agricultura no país acentua ainda mais a concentração da propriedade da terra e a desigualdade social no campo, com o alto preço de destruição da agricultura familiar, devastação e degradação dos empregos rurais, miséria da população rural e deterioração do meio ambiente.

Nas reuniões, os trabalhadores reconstruíram a história do assentamento, relataram a trajetória política do grupo (as condições de vida, antes, na antiga fazenda, e agora, no assentamento). Ressaltaram a conquista da propriedade da terra e a organização da agricultura de forma familiar e coletiva. Usaram a expressão 'Devolver a vida' como símbolo de um sonho que se realizou com a posse da terra. Constata-se que o desenvolvimento do processo produtivo coletivo da terra é acompanhado por uma transformação da própria vida social, na qual o político, o econômico, o cultural e o afetivo se sobrepõem nas narrativas. 
Eu queria resgatar uma coisa: na época da Fazenda Itamaraty, era grão e gado de corte, e disso aqui graças à reforma agrária nós conseguimos resgatar a vida, que é isso aqui. Nossas crianças que também na época não existiam aqui. Houve essa transformação: o leite, o feijão, o arroz, que na época era só soja para exportação, e nós conseguimos plantar outras coisas. Por isso que nós colocamos esse título: de volta para a vida. Volta de alguns animais; não tinha tatu; a volta dos pássaros! As árvores nascem no meio do pasto. Conseguimos diversificar a produção, e a vida mesmo é o verde. Estamos tentando construir, começar por aqui. Mudou bastante em todo o assentamento. Onde vivia um, hoje vivem mais de três mil. Isso que é vida, mais espaço para construir (Trabalhador 5).

Com Caldart (2001), entende-se que os sem-terra se fortalecem como sujeitos e se firmam como identidade, à medida que suas ações conseguem pôr em questão certos valores e, ao mesmo tempo, afirmam outros, provocando as pessoas a pensar além da ação que enxergam. Cada vez que caem cercas, a sociedade é obrigada a se olhar e a discutir o tamanho das desigualdades, o tamanho da opulência e da miséria, o tamanho da fartura e da fome. Em uma ocupação de latifúndio, há um valor posto em questão: o da propriedade em si mesma.

Para Hardt e Negri (2002), as forças que prefiguram novas formas democráticas e novos poderes constituintes da história estão sendo realizadas com muita resistência e muita luta. Essas forças contribuem para uma nova cartografia do global, que contesta 'O Império' e é também marcada por movimentos capazes de construir novos modos de produção.

\section{Agrotóxico: acidentes e riscos nas atividades de trabalho}

Ao debatermos o trabalho e a saúde no assentamento, um tema que também mobilizou as pessoas foi relativo ao uso de agrotóxicos. Chamou-nos a atenção a naturalização dos riscos em face da exposição a esses agentes químicos e a outros que foram recorrentemente citados, como picadas de animais e exposição direta ao sol:

O pessoal da roça tem deficiência, uns têm costume de calçar botina e outros não, usam chinelos. Mexem com ferramentas e correm o risco de serem picados por algum animal peçonhento, e ainda os que vão trabalhar na roça vão diretamente ao sol. Não colocam nem chapéu, a proteção maior é o uso de boné. Outros se esquecem do boné e não usam camisa de manga comprida. Aqui já aconteceu que, quando estavam passando veneno na lavoura, estavam em seis pessoas e cinco tiveram que ser levados para o posto de saúde urgente. Teve caso de criança mexendo em frascos de veneno, brincando perto. E o normal é isso mesmo, os homens têm que trabalhar, e vai. Nós não temos esses cuidados (Trabalhador 6). 
Para Bedor et al. (2009), a baixa percepção das situações de riscos a que estão expostos o trabalhador rural e também o seu coletivo é uma questão presente no conjunto de vulnerabilidades existentes no âmbito do uso dos agrotóxicos. Reconhecer os condicionantes sociais, culturais e econômicos presentes no processo produtivo agrário químico-dependente é uma necessidade para minimizar os danos à saúde e ao ambiente decorrentes dos agrotóxicos. Ao dialogar com os trabalhadores, o que se pôde notar é que eles têm algumas noções a respeito dos cuidados que devem ser tomados com agrotóxicos, porém a maioria não os coloca em prática.

É uma escala, mas geralmente são sempre as mesmas pessoas que vão. Porque elas têm mais costume de aplicar, quem tem mais experiência, mesmo se colocar um aprendiz, um cara que sabe tem que estar junto, porque uma aplicação de veneno se você fez mal você pode comprometer uma lavoura inteira (Trabalhador 6).

No relato a seguir, o trabalhador menciona que já sofreu uma intoxicação que quase o matou. Descreveu que foi um período muito difícil de sua vida. Relatos da literatura indicam que a cada caso de intoxicação aguda há uma expectativa de oito casos de intoxicação crônica. Mesmo sendo o Brasil um dos principais países consumidores de agrotóxicos na América Latina, ainda se observa grande escassez de informações sobre os efeitos decorrentes da exposição humana a esses compostos (Bedor et al., 2009).

$\mathrm{Eu}$, a mulher e o Claudemir [filho], na época tinha oito anos, fomos passar o veneno; tava escurecendo e era 100, 120 metros de cabeça baixa. Quando eu enchi a segunda bomba, já me senti mal, não aguentei, apliquei toda ela, encostei, me agachei no meio da casa, a mulher perguntou: do que foi? Eu disse: o veneno me pegou. Sentei no meio da casa a fiquei, e daí não consegui levantar mais (...). Aí eu fui pra Foz do Iguaçu; tava intoxicado mesmo. Aí atacou tudo, rim, fígado, dor de cabeça direto, urina solta; aí fui para Cascavel, fiquei internado 14 dias. Tomei muito soro, foi um ano de sofrimento até eu recuperar... Só o rim que não prestou mais (Trabalhador 7).

Constatou-se que existe muita falta de informação e diálogo em relação ao uso de equipamentos de proteção individual (EPI's) e dos efeitos do agrotóxico sobre a saúde. Os trabalhadores desconheciam as reais consequências a que uma exposição continuada pode levar, inclusive ao câncer (Peres e Moreira, 2003). Sem entrar na discussão da eficácia dos equipamentos de proteção individual, de modo geral, o fato de nos locais de trabalho estes nem sempre estarem apropriados, ou serem insuficientes para a manipulação de produtos químicos, revela que os trabalhadores se mostram ainda mais vulneráveis às exposições nocivas dos agrotóxicos. A pulverização dos 
agrotóxicos, seja por trator, seja por costal ou tração animal, é o meio empregado para aplicação dos produtos, acarretando exposição e desconforto, posto que os EPI's disponibilizados para os trabalhadores não estão adequados às condições. Estudos como o de Bedor et al. (2009), realizado com trabalhadores da fruticultura do Vale do São Francisco, indicam que os trabalhadores que não usavam o EPI ou o utilizavam de maneira incompleta sofreram mais intoxicação. Porém, o fato de usar o EPI não interferiu na proteção esperada para a intoxicação por agrotóxico.

Existe falta de informação. A máscara [EPI] a gente não consegue usar por causa do calor, que é muito grande. Com máscara, a gente não consegue trabalhar. A gente escolhe sempre as horas sem vento, é uma aplicação mais eficiente, pega melhor na lavoura; ai é pior porque sem vento você respira o veneno mesmo, e com o calor chega a ponto de você não agüentar mais e te obriga a tirar a máscara. Então você tira e põe a máscara; é pior porque você põe a mão na máscara. Então, às vezes eu passo veneno assim sem máscara; tenho medo. Eu vejo companheiro aqui que fuma com a mão toda suja de veneno (Trabalhador 7).

De acordo com Sarcinelli (2003, p. 44), uma situação digna de nota é a da exposição das mulheres trabalhadoras rurais ao agrotóxico. Para esses autores, as mulheres vivem aquilo que descrevem como "via de exposição somatória ao agrotóxico", que vai desde o transporte de contaminantes (agrotóxicos) do local de trabalho para dentro das casas até a lavagem e a higiene das roupas. Os autores chamam a atenção ainda para a possibilidade de a mãe transferir resíduos para o bebê (ainda na vida intrauterina) e por meio do leite materno.

Eu lavo separado, não por causa do veneno, mas por causa da roça; é mais suja, então a gente lava separada (Trabalhador 4).

Ouvimos ainda relatos a respeito de crianças que brincavam com o agrotóxico. A esse respeito, Sarcinelli (2003, p. 44) afirma que as crianças que são residentes em áreas rurais podem sofrer "exposição múltipla" a esses contaminantes químicos. Elas são expostas pelas casas no meio das lavouras, escolas, pelo modo de organização do trabalho dos pais, por rotas como ar, água e solo. E ainda citamos a questão das embalagens vazias de agrotóxicos que podem cair nas mãos das crianças e do convívio em locais onde são armazenados agrotóxicos. Ademais, a exposição do feto e da criança pode gerar lesões no cérebro, doenças neurológicas e retardo mental, sendo designada pela autora como "ameaça silenciosa dos agrotóxicos" (Sarcinelli, 2003, p. 44). Como mencionado anteriormente, um aspecto relevante no trabalho rural brasileiro diz respeito à participação de crianças e adolescentes nas atividades de trabalho agropecuárias. De acordo com Silva et al. (2005), 
o Censo Agropecuário, de 1996, informa a existência de 2.435.678 trabalhadores menores de 14 anos de idade atuando neste setor, ou seja, 18,6\% da população economicamente ativa (PEA) rural ocupada. Ainda segundo Silva et al. (2005), essa faixa da população é especialmente afetada pelo trabalho precoce, tanto pelos aspectos técnicos dos processos de trabalho (exposição aos agrotóxicos, às radiações solares, ao ruído, à vibração etc.) como também por aqueles ligados à organização do trabalho (jornada, ritmo, conteúdo das tarefas etc.). Além disso, é preciso considerar o comprometimento do processo de socialização infantil e da escolarização.

Os resultados disponíveis permitem afirmar que os principais fatores responsáveis pelos níveis de contaminação encontrados atualmente são a inexistência de uma política mais efetiva de fiscalização/aconselhamento técnico adequado na utilização dos agrotóxicos; o baixo nível de escolaridade, que torna difícil o entendimento, mesmo que superficial, de informações técnicas; as práticas exploratórias de propaganda das firmas produtoras; o desconhecimento de técnicas alternativas e eficientes de cultivo; a pouca atenção dada ao descarte de rejeitos e de embalagens; a utilização dos agrotóxicos e a exposição continuada a esses produtos (Peres e Moreira, 2003). Para Castro e Confalonieri (2005), em estudo efetuado em quarenta propriedades rurais de Cachoeiras de Macacu (RJ) acerca da percepção de risco e das práticas de uso dos agrotóxicos, em razão da natureza multifacetada do problema do uso abusivo de agrotóxicos no país, apenas uma ação multissetorial de médio a longo prazos seria capaz de reduzir os impactos negativos dessas substâncias.

As ideias de ações educativas continuam como forma de restaurar o diálogo com o homem do campo, pois apesar do avanço tecnológico e do desenvolvimento dos saberes das ciências humanas e sociais, não foi possível observar, no campo, uma aproximação entre técnicos e agricultores, no sentido de se produzir e compartilhar conhecimento relativo ao trabalho e à saúde do trabalhador rural.

\section{Considerações finais}

Ante os objetivos propostos, foi possível identificar e problematizar aspectos importantes sobre a relação saúde e trabalho dos integrantes do MST. Foi possível colocar em prática uma teoria do conhecimento, por meio da utilização do método Paulo Freire, que tem como dimensão principal a natureza dialógica da produção do saber, um saber organizado com base na relação comunicativa. Os problemas foram relacionados de forma participativa pelos trabalhadores, levando-os à condição de sujeito do estudo, apresentando propostas e compartilhando novas ideias com outros trabalhadores. 
Foi possível conhecer os relatos sobre a trajetória do grupo de trabalhadores, sua história e formação, o processo de trabalho realizado no assentamento, as queixas de saúde, a relação entre meio ambiente e modo de produção e os riscos de acidentes com agrotóxicos ocorridos com os trabalhadores rurais no assentamento. A noção de saúde que advém dos diálogos com os trabalhadores contribuiu para a superação das rígidas demarcações entre sentimentos que, apesar de aparentemente ambíguos e opostos, estão estreitamente relacionados entre si, como sofrimento/prazer, adoecimento/vida, violência/conquista. Com Gadamer (2006), entendemos que saúde é o próprio ritmo da vida, um processo contínuo, no qual o equilíbrio sempre volta a se estabilizar: “É que saúde é estar-aí, é estar-no-mundo, estar-com-pessoas, sentir-se ativa e prazerosamente satisfeitos com as próprias tarefas da vida" (Gadamer, 2006, p. 118).

Ressaltaram-se valores humanistas como justiça social, o uso coletivo da terra e a organização equitativa da produção. Foi possível contribuir para a construção de uma acepção de trabalho baseada em relações solidárias e cooperativas e na valorização de um sistema de gestão que se apoia em decisões com a participação direta dos trabalhadores. Realizamos debates a respeito de trabalho, gênero e geração realçando valores éticos que superem as rígidas hierarquias de poder perpetradas em nossa cultura. Verificamos o sentido simbólico que a palavra assentamento pode assumir como uma nova cartografia política e social do cenário agrário do país.

A posse da terra tem um forte significado de realização e de formação de identidade. Ser um 'sem-terra assentado' é ter o sentido da vida conquistado. Quanto ao uso dos agrotóxicos, vimos que ainda há muito por se fazer, como a superação da banalização dos acidentes e a crítica à situação de vulnerabilidade de saúde e trabalho da população do campo.

As mudanças efetivas no assentamento ainda não estão visíveis. Os trabalhadores relataram que o governo cedeu as terras, mas ainda faltam incentivos em muitas áreas, como saneamento básico, financiamentos para compra de insumos e principalmente apoio em relação à saúde. Tivemos a percepção de que esta pesquisa foi o início - com o estímulo ao diálogo entre trabalhadores e pesquisadores -, sendo necessário, assim, dar continuidade a esse processo de mudanças e construir novos preceitos a respeito da relação entre saúde e trabalho rural no âmbito da saúde coletiva. 


\section{Nota do Editor}

Este artigo relata parte do estudo realizado na monografia intitulada Do império para a vida, da porteira fechada ao território livre: as relações entre saúde e trabalho de pequenos produtores rurais do Movimento dos Sem TerraMST (Bernardes, Fontoura Júnior e Pereira, 2006), desenvolvida no âmbito do Curso de Especialização em Saúde do Trabalhador de Mato Grosso do Sul. Uma parceria entre o Centro de Estudos da Saúde do Trabalhador e Ecologia Humana, Escola Nacional de Saúde Pública Sergio Arouca, Fundação Oswaldo Cruz (Cesteh/Ensp/Fiocruz) e a Escola de Saúde Pública Davi Nasser/MS, foi aprovada pelo Comitê de Ética em Pesquisa da Ensp/Fiocruz.

\section{Colaboradores}

Eduardo Espíndola Fontoura Júnior realizou a proposta do estudo, participou da redação, do levantamento e da análise dos dados; Kátia Reis de Souza orientou a pesquisa, contribuiu com a redação, a análise e a discussão dos dados do artigo; Rogério Dias Renovato e Cibele de Moura Sales trabalharam na concepção e na redação do artigo. Os autores declaram que não há conflito de interesses.

\section{Notas}

1 Professor da Universidade Estadual de Mato Grosso do Sul (UEMS), Dourados, Mato Grosso do Sul, Brasil. Mestre em Ciências da Saúde pela Universidade de Brasília (UnB). $<$ eduardoespindola@terra.com.br> Correspondência: Rua Alcides Claus, 800, CEP 79823-462, Parque Alvorada, Dourados, Mato Grosso do Sul, Brasil.

2 Pesquisadora do Centro de Estudos da Saúde do Trabalhador e Ecologia Humana da Escola Nacional de Saúde Pública Sergio Arouca (Cesteh/Ensp/Fiocruz), Rio de Janeiro, RJ, Brasil. Doutora em Saúde Pública pela Ensp/Fiocruz.<katreis@ensp.fiocruz.br>

3 Professor adjunto da Universidade Estadual de Mato Grosso do Sul (UEMS), Dourados, Mato Grosso do Sul, Brasil. Doutor em Educação pela Universidade Estadual de Campinas (Unicamp).<rrenovato@uol.com.br> 
4 Professora titular da Universidade Estadual de Mato Grosso do Sul (UEMS), Dourados, Mato Grosso do Sul, Brasil. Doutora pelo Programa Multi-institucional de Ciências da Saúde da Universidade de Brasília (UnB). <cibele@uems.br>

\section{Referências}

BEDOR, Cheila N. G. et al. Vulnerabilidades e situações de riscos relacionados ao uso de agrotóxicos na fruticultura irrigada. Revista Brasileira de Epidemiologia, São Paulo, v. 12, n. 1, p. 39-49, 2009.

BERNARDES, Cláudia Deolinda Ortiz; FONTOURA JÚNIOR, Eduardo Espíndola; PEREIRA, Eunice Nunes. Do império para a vida, da porteira fechada ao território livre: as relações entre saúde e trabalho de pequenos produtores rurais do Movimento dos Sem Terra-MST. Monografia (Especialização) - Escola Nacional de Saúde Pública Sergio Arouca/Fiocruz, Rio de Janeiro, 2006.

BRANDÃO, Carlos Rodrigues. Pesquisa participante. São Paulo: Brasiliense, 1986.

. A pesquisa participante e a participação da pesquisa. In: BRANDÃO, Carlos Rodrigues; STRECK, Danilo R. Pesquisa participante: o saber da partilha. São Paulo: Ideias \& Letras; 2006. p. 21-54.

CALDART, Roseli Salete. O MST e a formação dos sem-terra: o movimento social como princípio educativo. In: GENTILI, Pablo; FRIGOTTO, Gaudêncio (Orgs.). A cidadania negada: políticas de exclusão na educação e no trabalho. São Paulo: Cortez, 2001. p. 125-144.

CAMPOS, Augusto. Violência e trabalho. In: MENDES, René (Org.). Patologia do trabalho. São Paulo: Atheneu, 2002, p. 1.6411.656 .

CASTRO, Jane S. M.; CONFALONIERI, Ulisses. Uso de agrotóxicos no município de
Cachoeiras de Macacu (RJ). Ciência \& Saúde Coletiva, Rio de Janeiro, v. 10, n. 2, p. 473482, 2005.

COMPARATO, Bruno K. A ação política do MST. São Paulo em Perspectiva, São Paulo, v. 15, n. 4, p. 105-118, 2001.

CORREIA, Luciana O. et al. Movimentos sociais e experiência geracional: a vivência da infância no Movimento dos Trabalhadores Sem Terra. Educação em Revista, Belo Horizonte, n. 46, p. 143-166, 2007.

DEERE, Carmen D. Os direitos da mulher à terra e os movimentos sociais rurais na reforma agrária brasileira. Revista de Estudos Feministas, Florianópolis, v. 12, n. 1, p. 175 204, 2004.

FREIRE, Paulo. Criando métodos de pesquisa alternativa: aprendendo a fazê-la melhor através da ação. In: BRANDÃO, Carlos Rodrigues. Pesquisa participante. São Paulo: Brasiliense, 1986.

Pedagogia do oprimido. Rio de Janeiro: Paz e Terra, 1988

HOBSBAWM, Eric. A era dos extremos: o breve século XX, 1914-1991. São Paulo: Companhia das Letras, 1995.

GADAMER, Hans-Georg. O caráter oculto da saúde. Petrópolis, RJ: Vozes, 2006.

GAJARDO, Marcela. Pesquisa participante: propostas e projetos. In: BRANDÃO, Carlos Rodrigues (Org.). Repensando a pesquisa participante. São Paulo: Brasiliense, 1987. p. 15-50. 
GILL, Rosalind. Análise do discurso. In: BAUER, Martin; GASKELL, George (Orgs.). Pesquisa qualitativa com texto, imagem e som. Petrópolis, RJ: Vozes, 2008. p. 244-270.

GRAMSCI, Antonio. A concepção dialética da história. Rio de Janeiro: Civilização Brasileira, 1986.

HARDT, Michel; NEGRI, Antonio. Império. São Paulo: Record, 2002.

MÉSZÁROS, István. O poder da ideologia. São Paulo: Boitempo Editorial, 2004.

OLIVEIRA, Rosiska D. Elogio da diferença: o feminino emergente. São Paulo: Brasiliense, 1992.

PERES, Frederico; MOREIRA, Josino C. É veneno ou é remédio? Agrotóxicos, saúde e ambiente. Rio de Janeiro: Editora Fiocruz, 2003.

SARCINELLI, Paula de Novaes. A exposição de crianças e adolescentes a agrotóxicos. In: PERES, Frederico; MOREIRA, Josino C. Moreira. (Orgs.). É veneno ou é remédio?: agrotóxicos, saúde e ambiente. Rio de Janeiro: Editora Fiocruz, 2003. p. 43-58.

SCOPINHO, Rosemeire A. Sobre cooperação e cooperativas em assentamentos rurais. Psicologia \& Sociedade, Porto Alegre, v. 19, n. esp., p. 84-94, 2007.

SILVA, Jandira M. et al. Agrotóxico e trabalho: uma combinação perigosa para a saúde do trabalhador rural. Ciência \& Saúde Coletiva, Rio de Janeiro, v. 10, n. 10, p. 891-903, 2005.
SILVA, Jeanne. Nos labirintos da lei: a retórica da reforma agrária no Estado Democrático de Direito - Brasil 1995/2006. Revista História, Franca, SP, v. 28, n. 2, p. 467-494, 2009.

STÉDILE, João Pedro. O latifúndio. In: SADER, Emir (Org.). Sete pecados do capital. Rio de Janeiro: Record, 2000. p. 161-214.

TERRA, Ademir. Reforma agrária por conveniência e/ou por pressão? Assentamento Itamarati em Ponta Porã-MS: “o pivô da questão". Tese (Doutorado em Geografia) Faculdade de Ciências e Tecnologia, Universidade Estadual Paulista, São Paulo, 2009.

TIRIBA, Lia V. Economia popular e produção de uma nova cultura do trabalho: contradições e desafios frente à crise do trabalho assalariado. In: FRIGOTTO, Gaudêncio (Org.). Educação e crise do trabalho: perspectivas de final de século. Petrópolis, RJ: Vozes, 1998. p. 189-216.

VENDRAMINI, Célia R. Educação e trabalho: reflexões em torno dos movimentos sociais do campo. Cadernos Cedes, Campinas, v. 27, n. 72, p. 121-135, 2007.

Recebido em 18/05/2011

Aprovado em 11/07/2011 